\title{
CAPÍTULO 09: AVALIAÇÃO DAS CONDICÕES HIGIÊNICO-SANITÁRIAS E QUALIDADE DA CARNE MOÍDA COMERCIALIZADA EM SERRA TALHADA-PE
}

\author{
CAPÍTULO 09: EVALUACIÓN DE CONDICIONES HIGIÉNICO-SANITARIAS Y \\ CALIDAD DE CARNES MOLIDAS COMERCIALIZADAS EN SERRA TALHADA- \\ PE
}

\begin{abstract}
CHAPTER 09: EVALUATION OF HYGIENIC-SANITARY CONDITIONS AND QUALITY OF MILLED MEAT COMMERCIALIZED IN SERRA TALHADA-PE
\end{abstract}

\author{
Shaenna Karlla de Souza Melo ${ }^{1}$; Daiana Oliveira Pereira ${ }^{2}$; Nadjaneide dos Santos Guerra ${ }^{3}$ Marileide de Souza \\ Sát; Keyla Laura de Lira santos ${ }^{5}$
}

DOI: $\underline{\text { https://doi.org/10.31692/978-65-88970-18-8.119-134 }}$

\begin{abstract}
RESUMO
A carne é um alimento fundamental ao desenvolvimento do organismo humano, apresentando alto valor nutricional. Diante disso, a carne moída vem sendo utilizada devido seu baixo custo e sua forma de preparo rápido e fácil, contudo deve-se ter cuidado no processamento para não contaminar a carne, utilizando-se das boas práticas de fabricação, as boas práticas de fabricação são importantes para obtenção de um produto de qualidade. O objetivo do trabalho foi analisar as condições higiênicosanitárias da carne moída comercializada na cidade de Serra Talhada. O estudo foi realizado no período de 11 de fevereiro a 02 de março de 2020. Foi utilizada uma lista de doze itens de conformidades, envolvendo aspectos da estrutura física dos locais de venda da carne. Foram avaliadas as condições higiênicas da carne moída de onze estabelecimentos comerciais de carne, sendo sete supermercados, três mercadinhos e um açougue. As condições de higiene dos estabelecimentos e manipulares foram avaliados de forma visual, durante a compra da carne moída, utilizando um check-list baseado na RDC $\mathrm{n}^{\circ}$ 275/2002 da ANVISA. Para avaliar a qualidade da carne moída foram determinadas a temperatura e $\mathrm{pH}$. Os dados foram submetidos à análise estatística descritiva e de variância. As principais irregularidades encontradas foram na temperatura das carnes e do local de manipulação. Os supermercados foram os mais contaminados, seguido dos mercadinhos e açougue. Foram encontradas inconformidades nos estabelecimentos e nos manipuladores de carne em descordo com RDC 275/2002 da ANVISA. É necessário maior fiscalização nos estabelecimentos a fim de garantir uma carne segura e de qualidade.
\end{abstract}

Palavras-Chave: Check-list, Estabelecimentos, Higiene.

\section{RESUMEN}

La carne es un alimento fundamental para el desarrollo del organismo humano, presentando un alto valor nutricional. En vista de esto, se ha utilizado carne picada por su bajo costo y su rápida y fácil preparación, sin embargo se debe tener cuidado en el procesamiento para no contaminar la carne, utilizando buenas prácticas de fabricación, buenas prácticas de fabricación. un producto de calidad. El objetivo del trabajo fue analizar las condiciones higiénico-sanitarias de la carne picada comercializada en la ciudad de Serra Talhada. El estudio se llevó a cabo del 11 de febrero al 2 de marzo de 2020. Se utilizó una lista de doce ítems de conformidad, involucrando aspectos de la estructura física de los lugares de venta de carne. Se evaluaron las condiciones higiénicas de la carne picada de once establecimientos cárnicos comerciales, incluidos siete supermercados, tres tiendas de abarrotes y una carnicería. Las condiciones de higiene de los establecimientos y manipuladores se evaluaron visualmente, durante la compra de carne picada, mediante un check-list basado en el RDC $n^{\circ}$ 275/2002 de ANVISA. Para evaluar la calidad de la carne

\footnotetext{
${ }^{1}$ Bacharelado em Zootecnia, Universidade Federal Rural de Pernambuco, shaennaflorestinha@ hotmail.com ${ }^{2}$ Bacharelado em Zootecnia, Universidade Federal Rural de Pernambuco, dayana_oliveira13@ @otmail.com ${ }^{3}$ Bacharelado em Zootecnia, Universidade Federal Rural de Pernambuco, nadjaneide_santos@ hotmail.com

${ }^{4}$ Mestranda em Zootecnia, Universidade Federal Rural de Pernambuco, marileidezootecnista@ hotmail.com

${ }^{5}$ Doutorado em Zootecnia, Universidade Federal Rural de Pernambuco, keylasantos@ gmail.com
} 
picada se determinó la temperatura y el pH. Los datos se sometieron a análisis estadístico descriptivo y de varianza. Las principales irregularidades encontradas fueron la temperatura de la carne y el lugar de manipulación. Los supermercados fueron los más contaminados, seguidos de las tiendas de abarrotes y las carnicerías. Se encontraron no conformidades en establecimientos y manipuladores de carne en desacuerdo con RDC 275/2002 de ANVISA. Se requiere una mayor inspección en los establecimientos para garantizar una carne segura y de calidad.

Palabras Clave: Lista de verificación, Establecimientos, Higiene.

\begin{abstract}
Meat is a fundamental food for the development of the human organism, presenting high nutritional value. Given this, ground meat has been used due to its low cost and its quick and easy preparation, however care must be taken in the processing so as not to contaminate the meat, using good manufacturing practices, good manufacturing practices. are important for obtaining a quality product. The objective of the work was to analyze the hygienic-sanitary conditions of ground meat sold in the city of Serra Talhada. The study was carried out from February 11 to March 2, 2020. A list of twelve conformity items was used, involving aspects of the physical structure of the meat sales locations. The hygienic conditions of the ground meat of eleven commercial meat establishments were evaluated, including seven supermarkets, three grocery stores and a butcher shop. The hygiene conditions of the establishments and handlers were assessed visually, during the purchase of ground meat, using a checklist based on RDC $n^{\circ} 275 / 2002$ of ANVISA. To evaluate the quality of the ground meat, temperature and $\mathrm{pH}$ were determined. The data were submitted to descriptive and variance statistical analysis. The main irregularities found were in the temperature of the meat and the place of handling. Supermarkets were the most contaminated, followed by grocery stores and butchers. Non-conformities were found in establishments and meat handlers in disagreement with ANVISA's RDC 275/2002. Greater inspection is required in establishments in order to guarantee safe and quality meat.
\end{abstract}

Keywords: Check-list, Establishments, Hygiene.

\title{
INTRODUÇÃO
}

A carne é um alimento fundamental ao desenvolvimento do organismo humano, é muito consumida, pois possui sabor agradável, apresentando também alto valor nutricional. Sendo formada por proteínas de alto valor biológico, ácidos graxos essenciais, saturados e insaturados, vitaminas do complexo B, minerais como fósforo, sódio, ferro, zinco, magnésio, potássio, além de ter grande importância para o setor econômico brasileiro (HANGUI et al., 2015).

Quando se fala em carne os consumidores são exigentes, os principais requisitos avaliados são a cor (que está relacionada com a mioglobina, proteína responsável pela coloração vermelha atraente), aliada à maciez, odor e sabor. Para os consumidores conscientes, a qualidade está relacionada com segurança do alimento, ou seja, a carne deve ser inócua, não trazendo riscos à sua saúde (GUARNIERI, 2002; MACEDO, 2009).

As boas práticas de fabricação são importantes para obtenção de um produto de qualidade. Segundo Resolução da Diretoria Colegiada, que trata dos Procedimentos Operacionais Padronizados Aplicados aos Estabelecimentos Produtores/Industrializadores de Alimentos (RDC no 275/2002) da Agência Nacional de Vigilância Sanitária (ANVISA), os 
estabelecimentos devem implementar e manter a higienização das instalações, equipamentos,

móveis e utensílios; realizar o controle de potabilidade de água assegurar a higiene e saúde dos manipuladores, garantir o uso de equipamento de proteção individual e realizar o manejo dos resíduos.

A moagem da carne deve acontecer em local limpo e próprio, sendo que a temperatura não deve ultrapassar $10^{\circ} \mathrm{C}$, o produto deverá sair do equipamento de moagem com temperatura nunca superior a $7^{\circ} \mathrm{C}$, e logo em seguida ser resfriado ou congelado. Para carnes congeladas a temperatura é de $-18^{\circ} \mathrm{C}$ e carnes resfriadas de 0 a $4^{\circ} \mathrm{C}$ (BRASIL, 2003). O pH é um parâmetro importante para avaliar a qualidade da carne, quando se encontra na faixa de 5,8 a 6,2 ela é considerada própria para consumo, 6,4 é utilizada para consumo imediato e quando está acima de 6,4 caracteriza início da decomposição (COSTA \& TANAMATI, 2014).

É importante conhecer a procedência da carne para que fique assegurado ser de qualidade.

Em tempos de pandemia é de fundamental importancia os estabelecimentos adotarem medidas para previnir a disseminação da COVID-19, podendo fazer uso de mascaras e luvas, sempre estando ciente que a luva não protege $100 \%$, então é importante fazer a correta higienzacão das mãos antes e após a manipulacao do alimento (BRASIL, 2020).

Objetivou-se avaliar as condições higiênico-sanitárias da carne moída comercializada em supermercados, mercados e açougues, na cidade de Serra Talhada.

\section{FUNDAMENTAÇÃO TEÓRICA}

A composição da carne está relacionada com o sexo do animal, raça, sistema de criação, maturidade e até mesmo o corte da carne. A composição físico-química apresenta teores mínimos de $19 \%$ de proteína, as substâncias nitrogenadas não protéicas totalizam $1,5 \%$, já o carboidrato é baixo, varia de 0,5 a 1,5\%. Os ingredientes obrigatórios da carne moída são as carnes obtidas de massas musculares esqueléticas de bovinos que pode ter a água como ingrediente opcional, no valor máximo de 3\%. A carne moída não possui coadjuvantes de tecnologia e o requisito físico-químico de gordura é de no máximo 15\%. (BRASIL, 2003; INSTITUTO ADOLFO LUTZ, 2008).

\section{Doenças transmitidas por alimentos (DTA)}

De acordo com o Ministerio da saude (2018) a Organização Mundial da Saúde (OMS) 
considera a DTA como um caso de preocupação de saúde pública global, devido causarem

doenças de uma a cada 10 pessoas,podendo ser fatal em crianças menores de 5 anos chegando a 420 mil mortes.

Segundo a Organização Pan-Americana da Saúde OPAS (2020) atualmente no mundo, estima-se que uma em cada dez pessoas adoecem após consumir alimentos contaminados, e que 420 mil pessoas morrem a cada ano, sendo que crianças menores de 5 anos são as mais afetadas, com 125 mil mortes anuais.

No período de 2009 a 2018, no Brasil foram notificados 2.431 surtos, sendo os principais agentes causadores de doenças a Escherichia coli, Salmonella spp, Staphylococcus aureus, coliformes, norovírus, rotavírus, shiguella, Bacillus cereus, Clostridium perfringens e vírus da Hepatite A, como pode notar-se na figura 01 (BRASIL, 2018).

Figura 01- Distribuição dos 10 agentes etiológicos mais identificados nos surtos de DTA Brasil, 2009 a 2018.

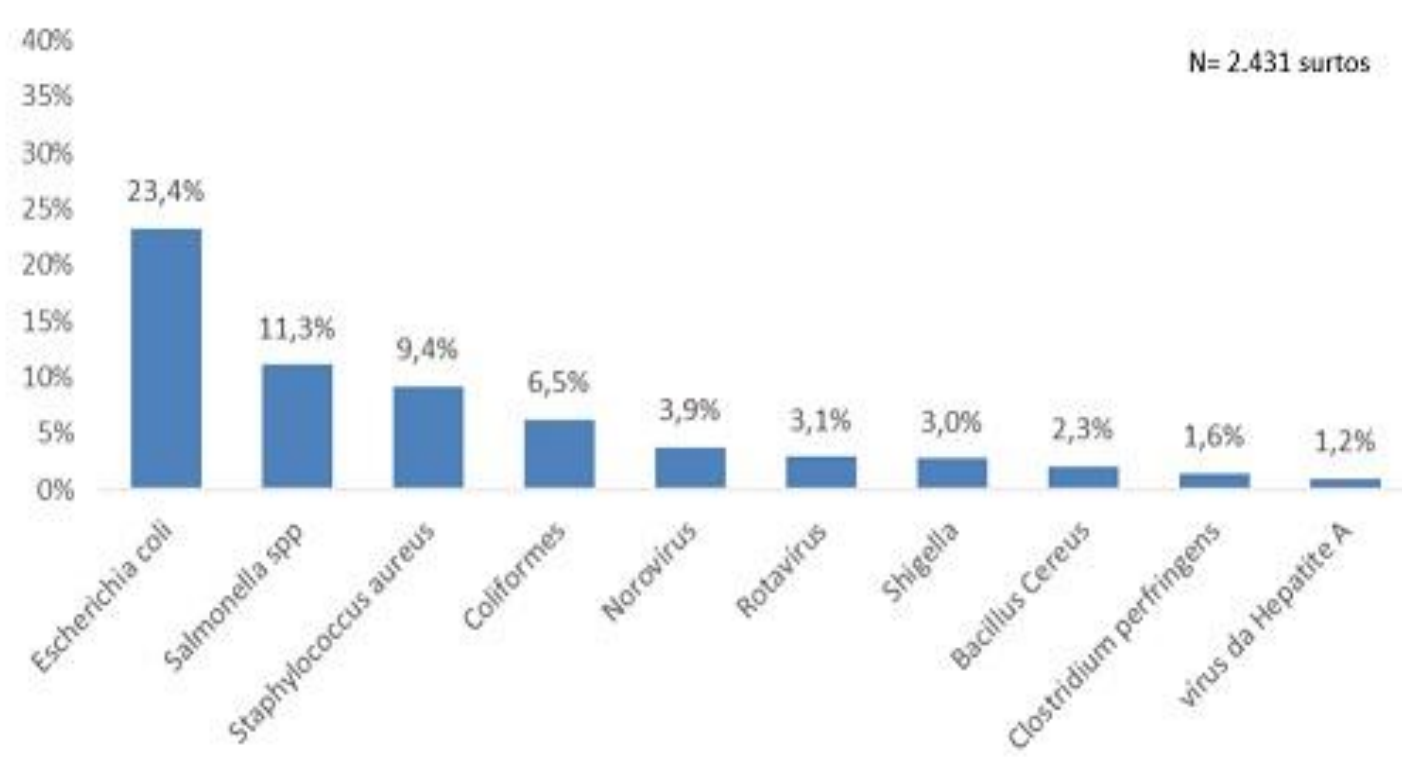

Fonte: Sinan/SVS/Ministério da Saúde.

Segundo dados epidemiológicos do Ministério da Saúde (Sinan net), em 2019 foram 1.227 casos de DTA notificados em Pernambuco, com 295 doentes, sendo o principal agente etiológico a Escherichia coli, Figura 02. 


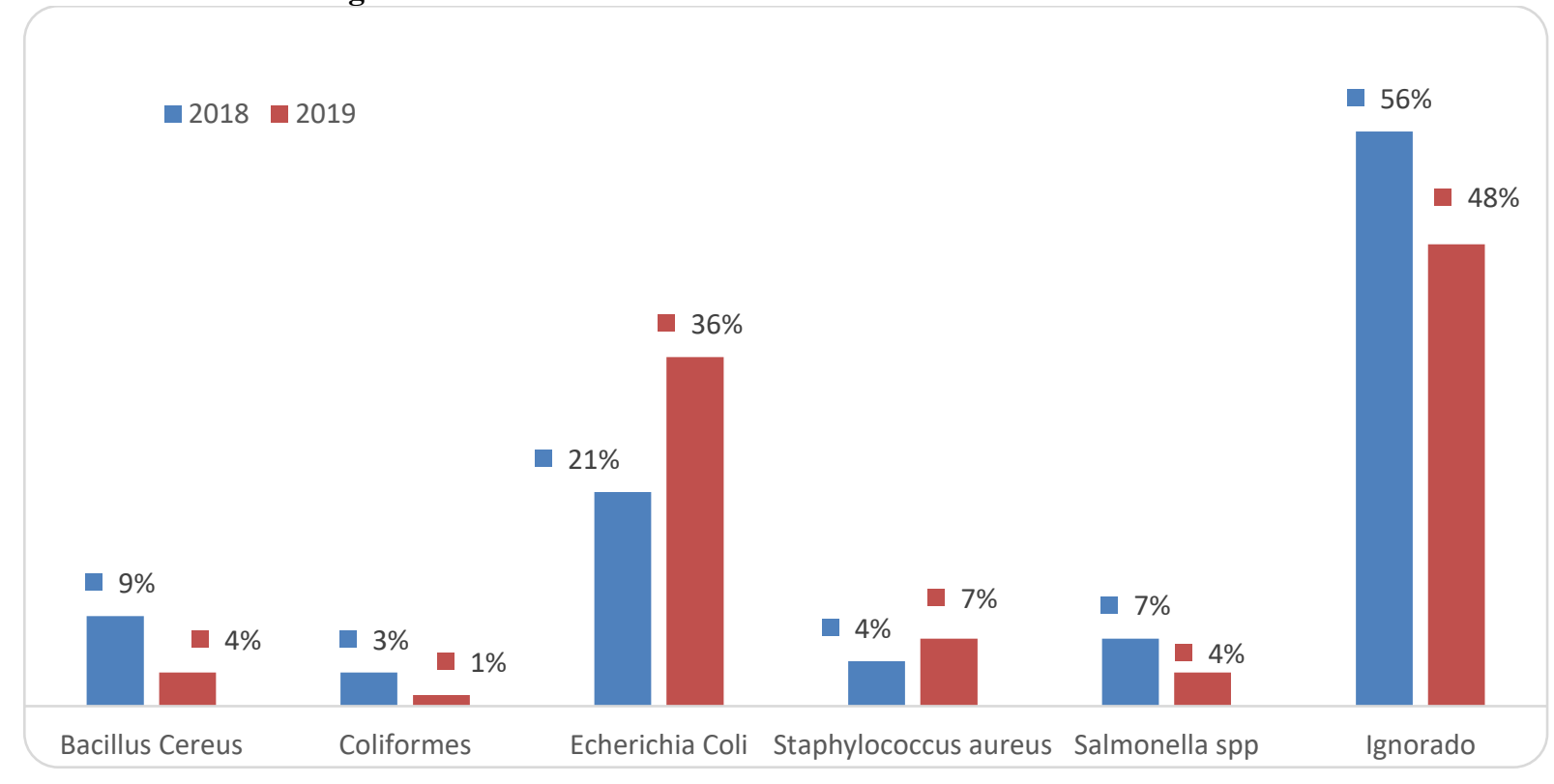

Fonte: Sinan/SVS /Ministério da Saúde

A contaminação microbiológica é a principal responsável pela falta de qualidade da carne, sendo imprescindível adotar medidas higiênico-sanitárias para combater possíveis surtos de doenças e ter uma fiscalização adequada para prevenir irregularidades cometidas por parte das indústrias.

\section{Principais agentes etiológicos causadores de surtos de doencas}

Salmonella é uma bactéria pertencente ao gênero da família Enterobacteriaceae, com sua forma de bacilos curtos, largura de 0,7 a $1,5 \mu \mathrm{m}$ e comprimento de 2 a $5 \mu \mathrm{m}$. O crescimento ocorre na temperatura de $35^{\circ} \mathrm{C}$, o $\mathrm{pH}$ varia entre 4 a 9, sendo $\mathrm{pH}$ ideal 7 e com atividade de água de 0,94. Essa bactéria é considerada um caso de saúde pública, devido o homem e animal serem considerados como um reservatório natural, acometendo todos os anos milhares de pessoas (MENDONÇA, 2016).

Staphylococcus aureus são bactérias anaeróbicas facultativas, Gram positiva, não esporulado, semelhante a um cacho de uva, não móveis, com alta resistência a ambientes secos. $\mathrm{O}$ pH ótimo é de 7,0 - 7,5, temperatura ideal de $37^{\circ} \mathrm{C}$, com atividade de água mínimo de 0,86 . Podendo ser encontrado em várias partes do corpo, como na garganta, fossas nasais e até mesmo no intestino de pessoas saudáveis, em geral sua contaminação está relacionada com problemas de falta de higiene do manipulador (TRABULSI \& ALTHERTHUM, 2015; FRANCO \& LANDGRAF, 2008).

Escherichia coli é uma bactéria anaeróbica facultativa, Gram negativa e não esporulada. 
Encontrada normalmente no organismo de aves e mamíferos, tem temperatura para crescimento

entre 8 a $48^{\circ} \mathrm{C}$, com temperatura ideal de $39^{\circ} \mathrm{C}$, pH entre 6,0 a 8,0 , e atividade de água 0,96 (FERENS \& HOVDE, 2011). De acordo com a Instrução Normativa nº 60/2019 da ANVISA, o limite microbiológico permitido é de $10^{2} \mathrm{UFC} / \mathrm{g}$.

Os microrganismos aeróbios mesófilos quando encontrados em grande quantidade é um indicativo de falta de higiene, esses microrganismos se desenvolvem em uma temperatura de $20^{\circ} \mathrm{C} \mathrm{e} 45^{\circ} \mathrm{C}$. Isso ocorre quando não se tem um transporte com temperatura e armazenamento correto, ocorrendo uma rápida multiplicação nos alimentos mal conservados (FRANCO \& LANDGRAF 2003; SILVA, 2002). Segundo a Instrução Normativa $n^{\circ}$ 60/2019 da ANVISA, o limite aceitável para microorganismo aeróbio mesofilos é $10^{5} \mathrm{UFC} / \mathrm{g}$.

Quando se pensa em produzir um alimento seguro para o consumo é importante utilizar as boas práticas de fabricação, levando em conta que com as Boas Praticas de Fabricação é possível identificar os principais problemas, realizando ações corretivas visando diminuir os riscos fisicos, quimicos e biológicos que afetam a saúde do consumidor (RODRIGUES et al., 2017; SILVEIRA et al., 2019).

É importante que os encarregados dos estabelecimentos garantam que as etapas de fabricação do produto de origem animal sejam efetuadas de forma segura e com higiene a fim de se obter produtos que atendam aos padrões de qualidade, não oferecendo risco a saúde, a segurança e interesse do consumidor. Deve ser feito a correta higienização dos utensílios e equipamentos sempre antes, durante e após serem utilizados (DECRETO № 9.013 MMAPA, 2017)

\section{METODOLOGIA}

A pesquisa do tipo qualitativa e quantitativa foi realiazado na cidade de Serra TalhadaPE, no período de 11 de fevereiro a 02 de março de 2020.

O municipio de Serra Talhada fica localizado na microrregião do pajeú, a $415 \mathrm{~km}$ da capital do Estado (Recife). Formado por 9 distritos e povoados, tem uma população estimada em 86.350 habitantes, área territorial de $2.980,007$ km² e conta com um bioma característico de caatinga (IBGE, 2019). Segundo a classificação de Köppen o clima da região é considerado Bswh, quente, Semiárido, com temperatura e precipitação anual de $26^{\circ} \mathrm{C}$ e $800 \mathrm{~mm}$, respectivamente (Companhia de Pesquisa de Recursos Minerais - CPRM, 2005).

Foram avaliadas às condiçoes higiênicas de onze estabelecimentos comerciais de carne. 
Os estabelecimentos foram escolhidos de forma aleatória, considerando os locais mais procurados de compras, sendo sete supermercados, três mercadinhos e um açougue (Figura 03).

Figuras 03- Locais dos estabelecimentos avaliados em Serra Talhada

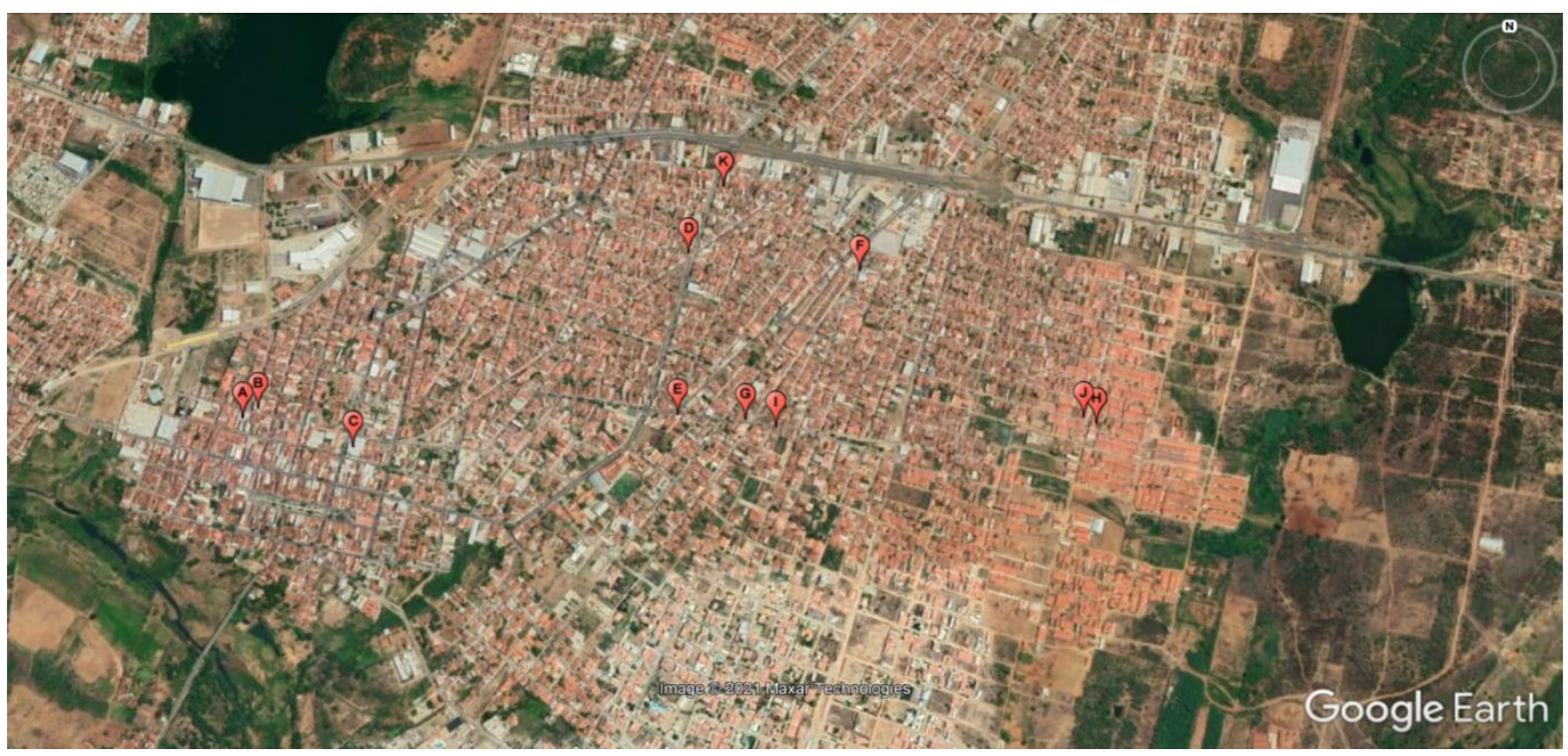

Fonte: Google Earth (2021)

As condições de higiene dos estabelecimentos e manipulares foram avaliados de forma visual, durante a compra da carne moída, utilizando um check-list baseado na RDC n 275/2002 da ANVISA e adaptado de SOUZA et al. (2012) .

Foi utilizada uma lista de doze itens de conformidades, envolvendo aspectos da estrutura física dos locais de venda da carne, uso adequado de equipamentos e de proteção individual dos manipuladores (Tabela 01). 
Tabela 01-Lista de verificação de conformidade e não conformidade das boas práticas de fabricação em estabelecimentos comerciais de carne (check-list).

\begin{tabular}{|l|l|l|l|}
\hline Local: & Tipo de corte: \\
\hline Horário da coleta: & Temperatura da carne: \\
\hline Data: Itens & Conformidade & \multicolumn{1}{|c|}{$\begin{array}{l}\text { Não } \\
\text { conformidade }\end{array}$} & Observações \\
\hline $\begin{array}{l}\text { Os balcões frigoríficos estão em bom } \\
\text { estado de conservação? }\end{array}$ & & \\
\hline $\begin{array}{l}\text { Há pragas e/ou animais no } \\
\text { estabelecimento comercializador de } \\
\text { carnes? }\end{array}$ & & & \\
\hline $\begin{array}{l}\text { As mesas utilizadas para o corte das } \\
\text { carnes são de aço inoxidável? }\end{array}$ & & & \\
\hline Temperatura das carnes & & & \\
\hline Lixeira com acionamento a pedal & & & \\
\hline Área organizada & & & \\
\hline Piso adequado & & & \\
\hline $\begin{array}{l}\text { O local de processamento é visível } \\
\text { para os clientes? }\end{array}$ & & & \\
\hline $\begin{array}{l}\text { Antes da manipulação é feito a } \\
\text { lavagem das mãos? }\end{array}$ & & & \\
\hline O local é limpo? & & & \\
\hline $\begin{array}{l}\text { Durante a manipulação as carnes são } \\
\text { mantidas refrigeradas? }\end{array}$ & & & \\
\hline $\begin{array}{l}\text { Os manipuladores trabalham com } \\
\text { roupas brancas e limpas? }\end{array}$ & & & \\
\hline
\end{tabular}

Fonte: Adaptado de SOUZA et al. (2012)

Os dados foram tabulados e calculados o percentual de conformidade e não conformidade dos itens avaliados na Tabela 01. Os estabelecimentos foram classificados de acordo a o percentual de adequações da RDC no 275/2002 em: grupo 1- Bom (76 a 100\% de adequações), grupo 2 - Regular (51 a 75\% de adequações) e grupo 3 - Deficiente (0 a 50\% de adequações)

A aferiçao da temperatura foi realizada no centro geométrico da carne, ao chegar ao laboratório, com auxílio de um termômetro digital infravermelho modelo Incoterm ST 500. Para o pH foram pesadas $10 \mathrm{~g}$ de cada amostra, adicionados $100 \mathrm{ml}$ de água, e sob agitação determinou-se o pH utilizando um pHmetro portátil (INSTITUTO ADOLFO LUTZ, 2008). Os dados foram submetidos à análise estatística descritiva e de variância, utilizando o programa estatístico SAS. 


\section{Avaliação das condições higiênico sanitárias}

Ao avaliar das condições de higiene dos estabelecimentos e manipulares durante a compra da carne moída, as principais irregularidades encontradas foram na temperatura das carnes e do local de manipulação, presenças de insetos, principalmente moscas, não realizavam a lavagem das mãos para a manipulação da carne e no uso de equipamento de proteção individual- EPI (incompleto ou ausente), Figura 04.

Figura 04- Avaliação das condições de higiene dos estabelecimentos e manipulares durante a compra da carne moída

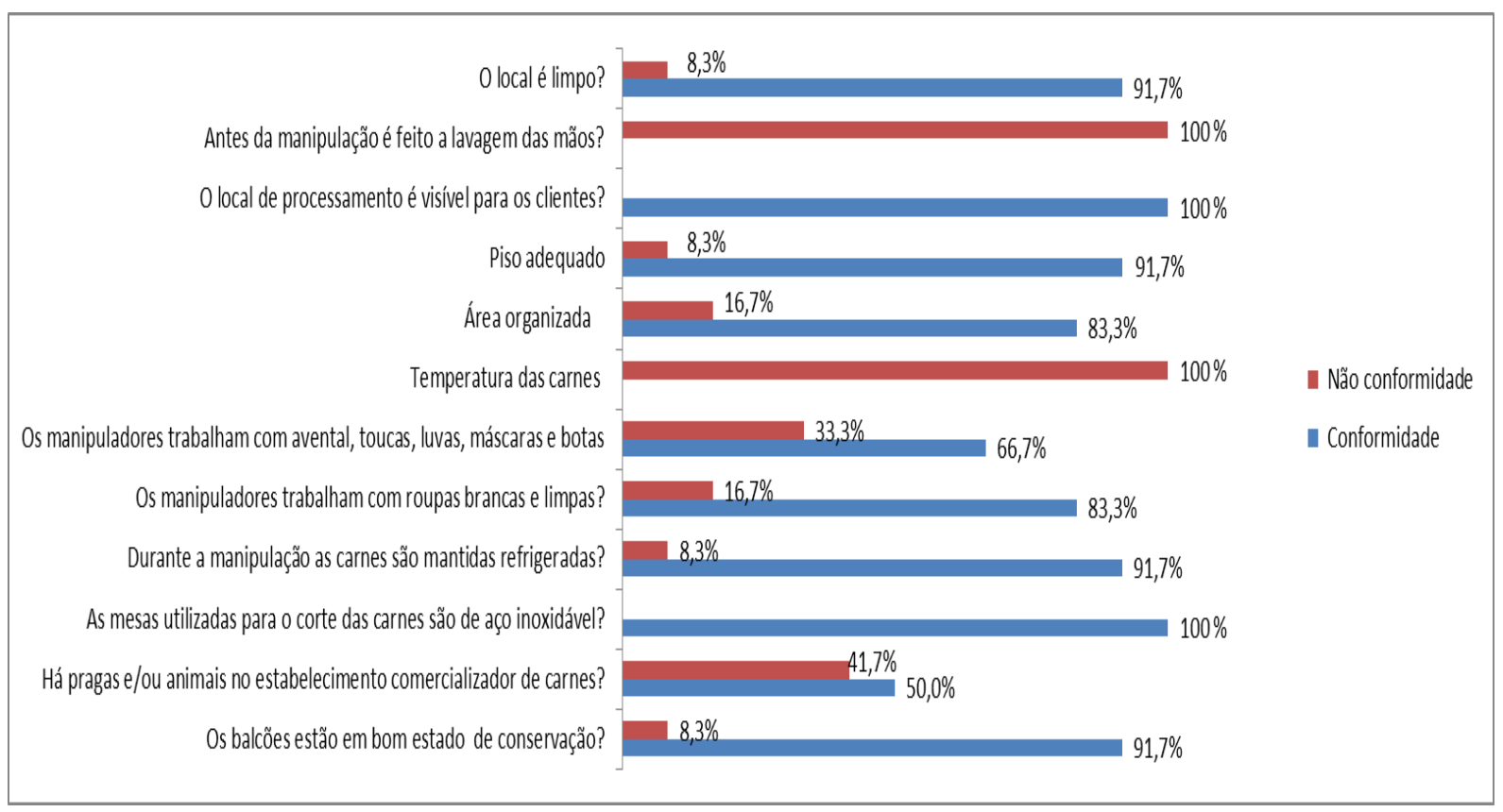

Fonte: própria (2020)

A falta de higienização durante a manipulação da carne pode ter contribuído para contaminação elevada por Salmonela encontrada nestes estabelecimentos (SHAENNA, 2020). Em relação à conformidade e inconformidade por estabelecimento foi possível observar que o supermercado $\mathrm{F}$ e mercadinho $\mathrm{J}$ obtiveram resultados acima de $75 \%$ de conformidade e o mercadinho G, ao contrário apresentou 66,7 \% de inconformidade (Figura 05).

Resultados diferentes foram encontrados na cidade de Santo Antônio de Jesus-BA, em que $60 \%$ dos supermercados tiveram menos que 50\% de conformidade (GOMES, 2011). 


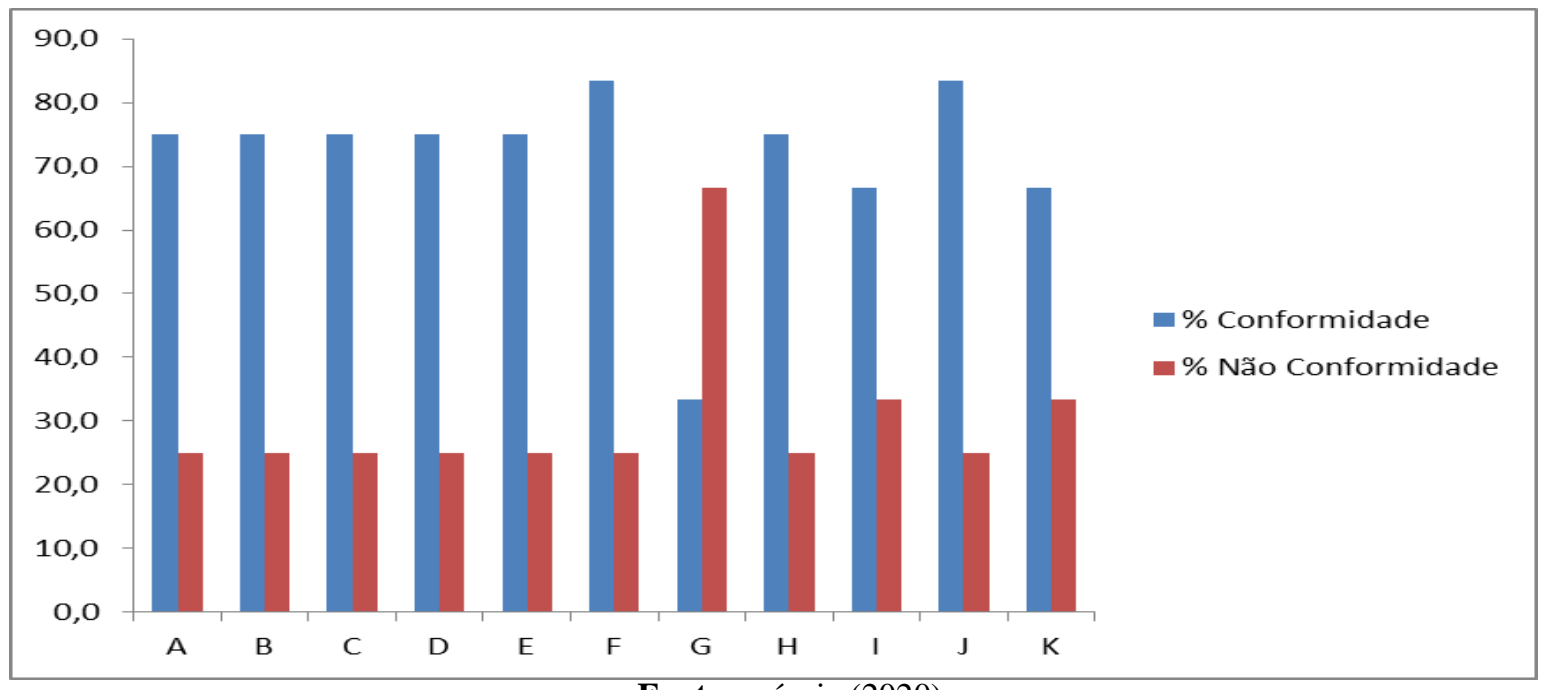

Fonte: própria (2020).

Dos onze estabelecimentos analisados $72,73 \%$ (8) foram classificados como regular, sendo em sua maioria composto pelos supermercados, e somente 18,18\% (2) como bom. Já os mercadinhos apresentaram maior variação quanto às boas práticas de fabricação com 9,09\% (1) classificado como deficiente (Figura 06).

Figura 06- Classificação dos estabelecimentos quanto as boas práticas de fabricação durante a compra da carne moída.

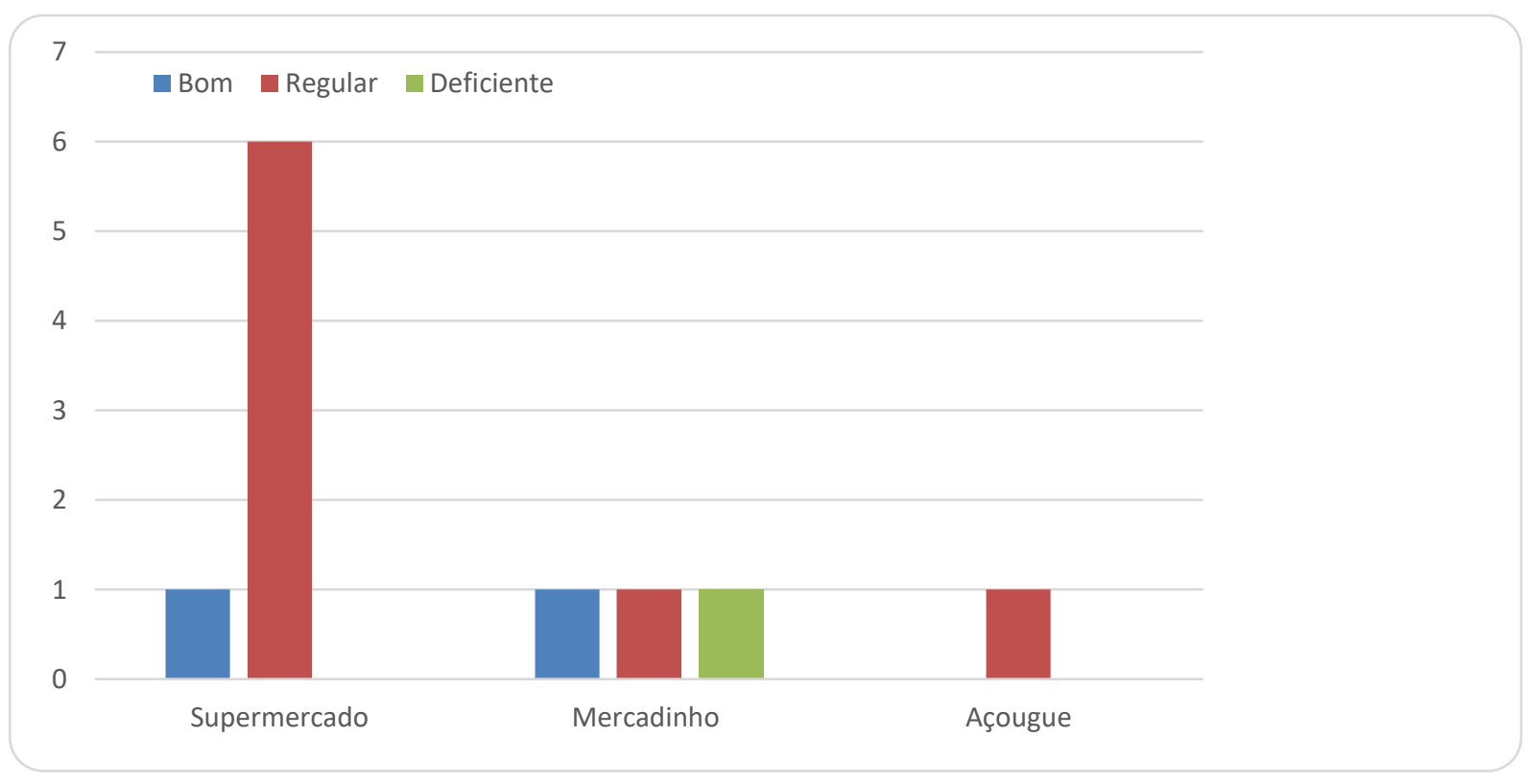

Fonte: própria (2020).

Os supermercados, mercadinhos e açougues obtiveram resultados como bom, regular e deficiente, sendo considerados como deficiente os estabelecimentos que causam riscos de 
contaminação para os alimentos segundo a RDC 275/2002 da ANVISA.

Pedroso \& Bernardino (2016) avaliaram três supermercados na cidade de Cascavel-PR, em que os supermercados 1 e 3 obtiveram conformidade de 84,62\% e o supermercado 2 atingiu $89,74 \%$, em relação a inconformidade o 1 e 3 tiveram $16 \%$ e o supermercado $210,26 \%$.

\section{Avaliação da temperatura e do pH da carne moída}

O pH da carne moída variou de 5,50 $\pm 0,14$ a 6,37 $\pm 0,21$ (Tabela 02). Das onze amostras coletadas dez estão de acordo com a legislação, onde é indicado que a carne para consumo tenha um pH na faixa de 5,5 a 6,2, quando o pH encontra-se acima de 6,4 sendo o limite crítico, ela está na fase de deterioração (BRASIL, 1997).

Mujica et al. (2015) verificaram que as amostras de carnes bovinas vendidas em quatro supermercados de Palmas -TO apresentavam pH de 5,12 a 5,48, que se caracteriza como permitido pelo Ministério da Agricultura.

Tabela 02 - Valores médios de temperatura e pH da carne moída

\begin{tabular}{lcr}
\hline Estabelecimentos & $\mathrm{pH}$ & Temperatura \\
\hline Supermercados & & \\
& & $8,05 \pm 0,07$ \\
$\mathrm{~A}$ & $5,70 \pm 0,01$ & $9,50 \pm 0,56$ \\
$\mathrm{~B}$ & $5,81 \pm 0,14$ & $8,00 \pm 0,01$ \\
$\mathrm{C}$ & $5,68 \pm 0,01$ & $8,80 \pm 0,14$ \\
$\mathrm{D}$ & $6,37 \pm 0,21$ & $8,95 \pm 0,07$ \\
E & $5,60 \pm 0,07$ & $6,80 \pm 0,35$ \\
F & $5,57 \pm 00,7$ & $8,20 \pm 0,01$ \\
G & $5,50 \pm 0,14$ &
\end{tabular}

Mercadinho e açougue

\begin{tabular}{lcr}
$\mathrm{H}$ & $5,75 \pm 0,07$ & $10,35 \pm 0,56$ \\
$\mathrm{I}$ & $5,58 \pm 0,14$ & $10,30 \pm 0,14$ \\
$\mathrm{~J}$ & $5,73 \pm 0,07$ & $7,50 \pm 0,14$ \\
$\mathrm{~K}$ & $5,58 \pm 0,01$ & $9,60 \pm 0,56$ \\
\hline $\mathrm{CV}(\%)$ & 1,15 & 4,06 \\
\hline
\end{tabular}

De acordo com Costa \& Tanamati (2018), carne com pH abaixo de 5,8 tem a qualidade superior devido a ter uma melhor suculência, maciez e coloração. Já em carne com pH superior a 6,4 elas se apresentam mais escuras e textura rígida.

Ferretto (2018) analisando o pH das amostras de carne moída de bovino verificou que os valores variam de 5,29 a 6,17 sendo a média das amostras de 5,83. 
Sczczepaniak \& Souza, (2020) também avaliando a carne moída comercializada em supermercados em Cuiabá-MT, encontraram pH na faixa de 5,8 a 6,2, indicando que a carne está boa para o consumo. Porém, apenas uma amostra apresentou pH 6,42, se enquadrando como carne imprópria e início de decomposição como preconiza legislação vigente.

Segundo Rodriguez (2016), quando o pH final é superior a 6,0 ocorre o esgotamento das reservas de glicogênio, que é influenciado pelo declínio do $\mathrm{pH}$ post-mortem, fazendo com e a carne se torne escura, pois vai está absorvendo a luz e assim ocorrendo uma alteração protéica ficando de qualidade inferior.

$\mathrm{O}$ pH é uma forma de conhecer se a carne é de qualidade, pois influência diretamente na multiplicação microbiana e retenção da água (ALCANTARA et al., 2012).

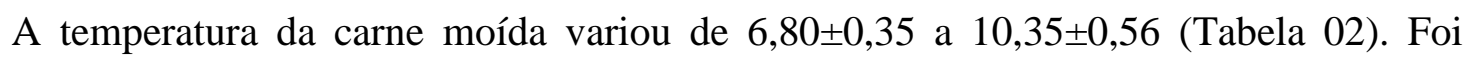
constatado que as onze amostras, nove estavam fora do padrão estabelecido pela Instrução Normativa $\mathrm{n}^{\circ} 83 / 2003$ do MAPA, que diz que a carne tem que ser resfriada de $0^{\circ}$ a $4^{\circ} \mathrm{C}$, e deverá sair do equipamento de moagem nunca superior a $7^{\circ} \mathrm{C}$, levando-se imediatamente ao congelador ou ao resfriamento. O que pode ter interferido nesse resultado foi à temperatura elevada da sala de moagem, que não estava em condições ideais.

Para garantir uma carne de qualidade é necessário ter uma padronização da temperatura para não interferir na qualidade do produto e em possíveis contaminações por microrganismos que diminuem o tempo de prateleira e causam riscos a saúde da população, sendo assim quanto menor o tempo de exposição, menor o risco de multiplicação de microrganismos (ANJOS, 2013; CINTRA et al., 2016).

Trabalhos recentes de Bonacina et al., (2017) sobre parâmetros indicativos da qualidade da carne bovina moída comercializada em diferentes supermercados em Erechim, Rio Grande do Sul, constatou que $100 \%$ das amostras estavam fora do padrão da Instrução Normativa ${ }^{\circ}$ 83/ 2003 do MAPA.

É importante que a carne esteja em uma temperatura correta, pois sua falta resulta em risco a saúde do consumidor, devido ter uma maior superfície de contato que a deixa mais exposta a possível contaminação, servindo como uma porta de entrada para microrganismos patogênicos (HANGUI et al., 2015; BAPTISTA et al. 2013).

\section{CONCLUSÕES}

Em relação aos estabelecimentos visitados eles apresentaram inconformidade nos quesitos de segurança alimentar, tanto para a temperatura, quanto para os itens do check-list 
(local de manipulação e presença de insetos). É necessário ter uma fiscalização adequada nos

estabelecimentos a fim de garantir uma carne segura e de qualidade. É importante organizar programas de capacitação para os comerciantes a fim de melhorar a qualidade do seu produto e a segurança para dos clientes.

\section{REFERÊNCIAS}

ALCANTARA, M.; MORAIS, I. C. L.; SOUZA, C. M. O. C. C. Principais Microrganismos envolvidos na deterioração das características sensoriais de derivados cárneos. Revista Brasileira de Higiene e Sanidade animal. v.6, n.1, p.1-18, 2012.

ANJOS, L. D. Modelos de crescimento psicrotróficos em diferentes temperaturas e pH. 2013.126f. Dissertação (Mestrado em Ciência de Alimento)- curso de pós-graduação em Ciências de Alimentos, Universidade Federal de Larvas, Lavras.

BAPTISTA RIAA, MOURA FML, FERNANDES MFTS. SANTOS VVM,FERNANDES EFTS. Aspectos qualitativos da carne moída comercializada na região metropolitana do RecifePE. Acta Veterinária Brasílica. n.7, v.1 ,p.38-47.

BONACINA, M.S., BACCIN, M. A. \& ROSA, L. S. Avaliação de parâmetros indicativos da qualidade da carne bovina moída comercializada em diferentes supermercados em Erechin, Rio Grande do Sul. Revista Vigilância Sanitária em debate, n,5, v,4, p.9-16, 2017.

BRASIL. Agência Nacional de Vigilância Sanitária (ANVISA). Instrução Normativa n⿳0 60 , de 26 de dezembro de 2019. Estabelece as listas de padrões microbiológicos para alimentos prontos. Diário Oficial [da] da República Federativa do Brasil, Brasília, dezembro 2019.

BRASIL. Ministério da Agricultura, Pecuária e do Abastecimento. Instrução Normativa no 83, de 21 de novembro de 2003. Regulamentos Técnicos de identidade e qualidade de carne bovina em conserva (corned beef) e carne moída de bovino. Diário Oficial da União, 21 nov. 2003, Seção 1, p. 29.

BRASIL. Ministério da Agricultura, Pecuária e Abastecimento. Regulamento da inspeção industrial e sanitária de produtos de origem animal. Brasília: Ministério da Agricultura, Pecuária e Abastecimento, 1997.

BRASIL. Agencia Nacional de Vigilância Sanitária (ANVISA). Resolução - RDC $\mathbf{n}^{\circ} \mathbf{2 7 5}$, de 21 de outubro de 2002. Dispõe sobre o regulamento técnico de procedimentos operacionais padronizados aplicados aos estabelecimentos produtores/industrializadores de alimentos e a lista de verificação das boas práticas de fabricação em estabelecimentos produtores/ industrializadores de alimentos. Diário Oficial da União, Brasília, 2002.

BRASIL. Ministério da Saúde. 2018. Surtos de doenças transmitidas por alimentos no Brasil. Brasília. Disponível em:http://portalarquivos2.saude.gov.br. Acesso em: 10.mai.2021.

BRASIL. Ministério da Saúde. Saúde de A a Z. Doenças transmitidas por alimentos: causas, sintomas, tratamento e prevenção. Ministério da Saúde, Brasília, DF, 2018. Disponível em: 
https://antigo.saude.gov.br/saude-de-a-z/doencas-transmitidas-por-alimentos,

20.abr. 2020

BRASIL. Agência Nacional de Vigilância Sanitária. (2020). NOTA TÉCNICA No 15/2020/SEI/GGALI/DIRE2/ANVISA - Uso de luvas e máscaras em estabelecimentos de área de alimento no contexto do enfrentamento da Covid-19. Brasília, março de 2020. Disponível em: https://www.abras.com.br/comites/juridico/noticias-juridicas/?materia=24211 acesso:10.mai.2021.

BRASIL. Ministério da Agricultura, Pecuária e do Abastecimento. Decreto n⿳0 9.013, de 29 de março de 2017. Dispõe sobre o regulamento da inspeção industrial e sanitária de produtos de origem animal. Brasília: Ministério da Agricultura, Pecuária e Abastecimento, 2017.

CINTRA, A. P. R; ANDRADE, M. C. G; LAZARINI, M.M; ASSIS,D.C.S; SILVA G.R; MENEZES, L.D.M;ORNELLAS C..D; FIGUEIREDO T.C; CANCADO,S.V. Influenc of cutting room temperature on the microbiological quality of chicken breast meat. Arquivo Brasileiro Medicina Veterinária e Zootecnia. v 68, n. 3 , p 814-820, 2016. Disponível em: http://doi.org/10.1590/1678-4162-8153.Acesso em: 20 de abri .2021

COSTA L. C., TANAMATI A. Avaliação higiênico-sanitária e físico-química de carne in natura comercializada em Campo Mourão - PR. Revista UNINGÁ, n.33, v.1 , p.55-65; 2018.

CPRM- Serviço Geológico do Brasil. Projeto de cadastro de fontes de abastecimentos por água. Diagnóstico do município de Serra Talhada -PE/ organizado por Mascaranhas, J.C.; Beltrão, B.A.; Junior, L.C .S.;Trindade, M.J.; Pereira, S. N.; e Miranda, J. F.; Recife: CP RM/P RO DE EM, 2005. 12p.

FERRETO, L. R. Qualidade da carne moída de bovino comercializada em Uruguaiana RS .Uruguaiana, 2018.46p. Tese (Doutorado em Medicina Veterinária)-Universidade Federal do Rio Grande do Sul. Disponível em: http// lume.frgs.br. Acesso em: 08. abri. 2021.

FERENS, W. A; HOVDE C. J. Escherichia coli O157:H7: Animal Reservoir and Sources of Human Infection. Food forne Pathogens and Disease, v.8, n. 4, p.465- 487. 2011.

FRANCO, B.D.G.M, LANDGRAF, M. Microbiologia dos alimentos. São Paulo: Atheneu; 2008. 182p

GOMES, A.P.P. Condições higiênico-Sanitárias e Físico-Estruturais de Supermercados que Comercializam Carne Bovina in natura no Município de Santo Antônio de Jesus-BA. Monografia apresentada à Universidade Federal Rural do Semiárido (UFERSA), Salvador, 2011.

GOOGLE. Google Earth website. http://earth.google.com/ , 2021

GUARNIERI, P. Bem estar animal e qualidade da carne. Uma exigência dos consumidores. Revista Nacional da Carne, v. n.26, p. 36-44, 2002.

HANGUI, S.A.R.; FERREIRA, A.F.; DOURADO, A.T.S.; MARTINS, J.D.; VARGEM, D.S.; SILVA, J.R. Análise microbiológica da carne bovina moída comercializada na cidade de Anápolis. Revista Eletrônica de Farmácia, v.12, n.2, p. 30-38, 2015.

IBGE - Instituto Brasileiro de Geografia e Estatística. Cidades e Estados. 2019. Disponível 
em: < https://www.ibge.gov.br/cidades-e-estados/pe/serra-talhada. Acesso em: 26 de abri. 2021.

INSTITUTO ADOLFO LUTZ. Métodos físico-químicos para análise de alimentos; São Paulo, SP: Instituto Adolfo Lutz; 2008.p. 1020.

MACEDO, R. E. F. Fraudes na comercialização de carnes e o risco para a saúde da população. Programa de Pós-Graduação em Ciência Animal -PPGCA - out. 2019- Curitiba. Anais... .Curso de MedicinaVeterinária PUCPR.

MENDONÇA, E. P. Características de virulência, resistência e diversidade genética de sorovares de Salmonella com impacto na saúde pública, isolados de frangos de corte no Brasil. Tese (doutorado). Universidade Federal de Uberlândia, Programa de Pós-Graduação em Ciências Veterinárias, 2016.

MUJICA, P.Y.C., NOGUERA, C. S. S., WANDERLEY, K. R. D. \& ANJOS, E. S. Qualidade físico-química do músculo bovino comercializado em quatro supermercados de Palmas-TO. Anais... In: $5^{\circ}$ Simpósio de Segurança Alimentar: Alimentação e Saúde. Bento Gonçalves., 2015, p. 1-3.

ORGANIZAÇÃO PAN-AMERICANA DA SAÚDE ORGANIZAÇÃO MUNDIAL DE SAÚDE, Dia Mundial da Segurança dos Alimentos, 2020. Disponível em https://www.paho.org/pt/campa\%C3\%B1as/dia-mundial-inocuidad-alimentos-2020. Acesso 08 de maio de 2021.

PEDROSO K.R.Q, BERNARDINO P.D.L.S. Aspectos higiênico-sanitários de estabelecimento comercial do tipo supermercado de grande porte. Revista Eletrônica Científica Inovação e Tecnologia. v. 1, n. 13, p. 68-82, 2016.

RODRIGUES T. P., SILVA T. J. P. Caracterização do processo de rigor mortis e qualidade da carne de animais abatidos no Brasil. Arquivos de Pesquisa Animal,v. 1 n. 1, p 1-20; 2016.

RODRIGUES, A.A.; SOUSA, W.L.; PINHEIRO, R.E.E. et al. Aspectos higiênico-sanitários de estabelecimentos comercializadores de carnes no município de Bom Jesus-PI.

Revista Brasileira de Higiene e Sanidade Animal, v.11, n.1, p.94-103, 2017.

SCZCZEPANIAK, C. V. M; SOUZA,C. O. S. S. Avaliação microbiológica e físico-química de carne bovina moída comercializada em supermercados de Cuiabá - MT. Brazilian Journal of Development. v. 6, n. 7, p. 53002-53018. 2020.

SILVA, M. C. Avaliação da qualidade microbiológica de alimentos com a utilização de metodologias convencionais e do sistema simplate. 2002. 87 P. Tese (Mestre em Ciências)Escola Superior de Agricultura, Universidade de São Paulo, 2002, Piracicaba.

SOUZA, V.S; SANTOS, R.C.A; BRITO,J.V.S. avaliação das condições higiênico-sanitárias de carnes comercializadas no município de nossa senhora da glória - SE. Anais... 2012. Nossa Senhora da Glória- SE.

SILVEIRA, D.R.; KAEFER, K.; PORTO, R.C. et al. Qualidade microbiológica de produtos de origem animal encaminhados para alimentação escolar. 
TRABULSI, L. R.; ALTERTHUM, F. Microbiologia. $6^{\text {a }}$ edição, São Paulo: Editora Atheneu. 2015. 888p. 